\title{
22. Enterprise Integration Engineering as an Enabler for Business Process Management
}

\author{
Arturo Molina ${ }^{1}$, Jorge Garza ${ }^{2}$, Guillermo Jiménez ${ }^{2}$ \\ 1CSIM-ITESM armolina@itesm.mx \\ 2 CII-ITESM garza.jorge@itesm.mx,guillermo.jimenez@itesm.mx
}

\begin{abstract}
This paper describes how Business Process Management has been implemented based on a Reference Framework defined based on Enterprise Integration Engineering concepts. The Reference Framework includes the following components: strategy definition (competitive, supply chain, operational), performance evaluation system, process design/re-design, and enabling technologies. It describes how all these issues have to be considered in an integrated way to align the company strategy with process improvement projects in order to achieve excellent performance. One case study is reviewed to describe how the reference model has been used in a OEM (Original Equipment Manufacturer) to achieve change management and best mamufacturing practices implementation.
\end{abstract}

\section{INTRODUCTION}

Emerging economies, social and political transitions, and new ways of doing business are changing the world dramatically. These trends suggest that the competitive environment for manufacturing enterprises in 2020 will be significantly different than it is today. To be successful in this competitive climate, manufacturing enterprises of 2020 will require significantly improved technological and organizational capabilities. The acquisition of these capabilities represents the challenge facing manufacturing. Two important concepts have emerged to support companies in this new challenging scenario (Vernadat 2002, Bernus et al. 2003, Grigoria et al. 2004):

Enterprise Integration Engineering (EIE) is the collection of modeling principles, methodologies and tools that allow to engineer different entities' life cycles in an enterprise (e.g. enterprise, project, product, processes). The foundation relies on the creation of models of the structure, function and behavior of the different entities. EIE allows a detailed description of all the key elements of an entity (activities, data/information/knowledge, organizational aspects, human and technological resources). In an enterprise model, this description provides the means to connect and communicate all the functional areas of an organization to improve synergy within the enterprise, and to achieve its mission and vision in an effective and efficient manner. 
Business Process Management (BPM) is the set of theories, techniques, methods, tools and applications that support the design and development of Business Process Management Systems (BPMS) which are software platforms that support the definition, execution, and tracking of business processes. Proper analysis of BPMS execution logs can yield important knowledge and help organizations improve the quality of their business processes, including the production of goods and services to business partners, as well as the enterprises' own management activities. This analysis is known as Business Process Intelligence.

Among all these issues, business process management, integration and coordination remain challenging because of its knowledge intensive nature. Therefore there is a need for systematic methodological- and technology-supported approach to develop and sustain a successful company.

This paper describes a Framework for Enterprise Integration Engineering that has been defined and developed to support Business Process Management in Mexican companies. An example based on a case study of an OEM company is presented to demonstrate the usage of the reference model.

\section{ENTERPRISE INTEGRATION ENGINEERING (EIE) REFERENCE FRAMEWORK}

\subsection{Components of the EIE Reference Framework}

The components of the reference model are depicted in Figure 1. Each of the different components provides guidelines, methodologies and tools to engineer business process changes. The components are:

- A strategy realization process and performance evaluation systems support the definition of three types of strategies in the company, namely: Competitive-, Value Chain- and Production/Service Strategy. All these strategies are associated with performance measures to evaluate the impact of the strategy pursued in the organization.

- Reference Models for Enterprise Modeling supports the visualization of enterprise knowledge, processes and associated performance measures in order to identify areas of opportunities for improvement.

- Decision making and simulation models support the evaluation of different strategies and implementation of best manufacturing practices using different simulation tools such as: dynamic systems and discrete event simulation. Best practices are defined in terms of logic program models to describe its impacts on business performance.

- Business Process Management Systems and Business Process Intelligence tools support the execution and analysis of process using business and IT perspectives. Business Process Management Systems allow process design, execution and tracking based on workflow technology. The Business Process Intelligence analysis supports decision making for predicting and optimizing processes. 

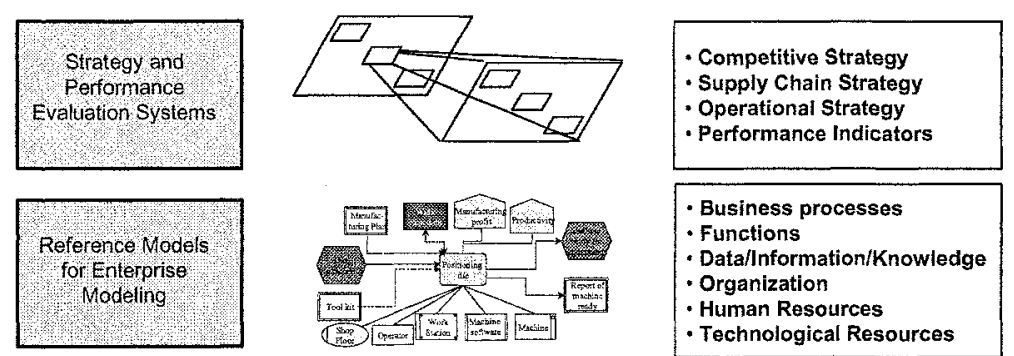

- Business processes

- Functions

- Data/Information/Knowledge

- Organization

- Human Resources

- Technological Resources
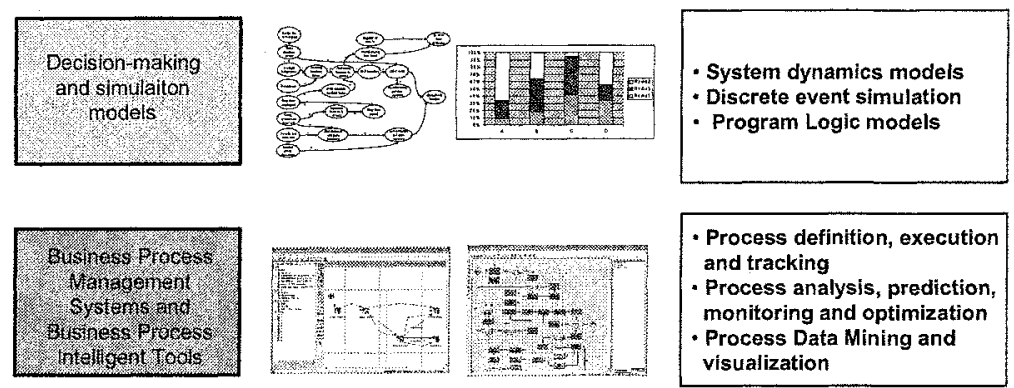

- Process definition, execution
and tracking
- Process analysis, prediction,
monitoring and optimization
- Process Data Mining and
visualization

Figure 1 Components of the Enterprise Integration Engineering Reference Framework for Business Process Management

\subsection{Strategy and performance evaluation systems}

Analysis tools and guidelines are provided to define three propositions to achieve competitive advantage: product innovation, operational excellence and customer focus (Hope and Hope 1997).

The competitive strategy should be translated into a set of decisions of how the organizations can deliver value to the customer. Value Chain strategy is about making decisions of how a company will establish an organizational model (external and internal) that will exploit the different possibilities to build an effective and efficient value chain. Different decisions can be conceived in value chain strategy: Vertical Integration, Structuring into Strategic Business Units, Horizontal Integration and Establishment of a Collaborative Organizational Structure.

The last strategy defines how the company will produce or deliver its products or services. The production/services strategy is based on the following factors: product description, characterization of customers and suppliers, and process definition. All these factors are defined by order-qualification and order-winning criteria (Hill 1989). The criteria are: price, volume, quality, lead-time, delivery speed and reliability, flexibility, product innovation and design, and life cycle status. Based on all these performance measures the following production strategies may be defined (Molina and Medina 2003):

- Production Strategy: Make to Stock (MTS), Make to Order (MTO), Assemble to Order (ATO), Configure to Order (CTO), Build to Order (BTO) and Engineer to Order (ETO).

- Service Strategy: Services on Catalogues (SoC), Configuration of Services (CoS) and Design of Services (DoS) 
The impact of these strategies in a company should be able to be measured using a performance evaluation system. Performance measures are defined in the following dimensions: Quality, Time, Cost, Volume, Flexibility and Environment. Figure 2 depicts the process of strategic decision making, using different analyses for strategic decisions and performance measures to evaluate their impacts.

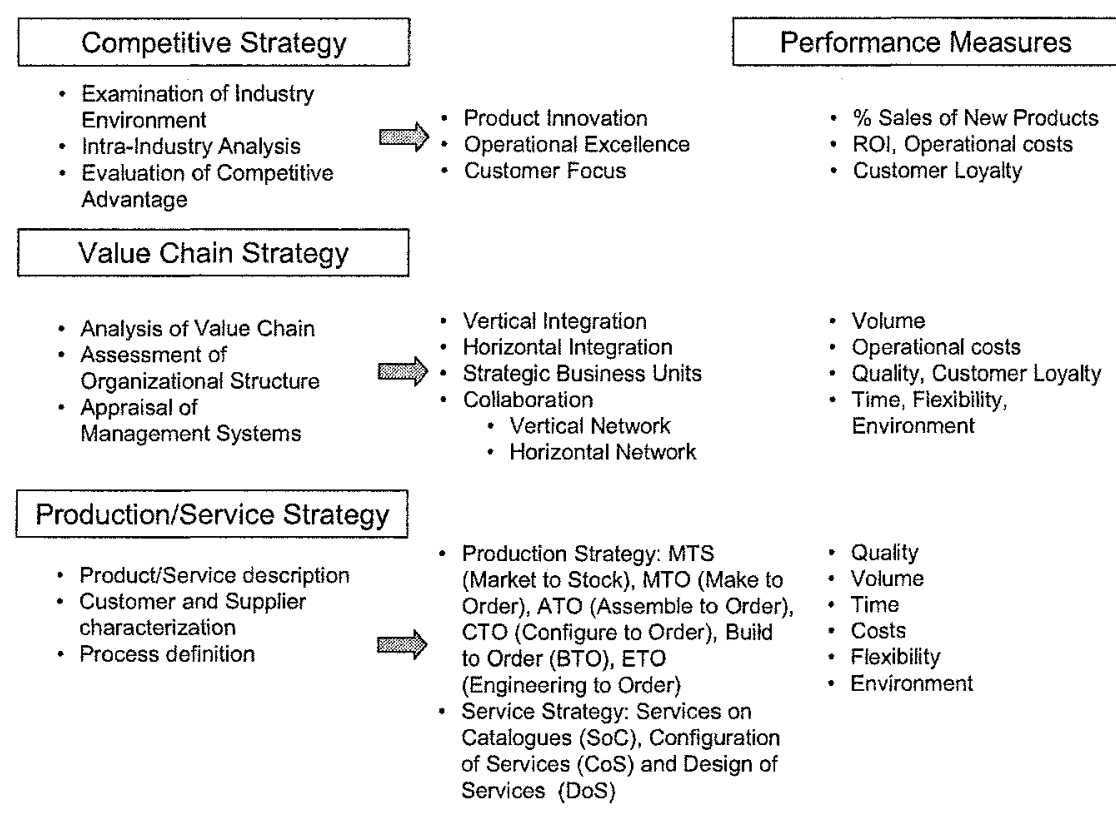

Figure 2 Guidelines for strategy definition process

\subsection{Reference Models and Enterprise Modelling}

The reference model used in this component, it is based on the Extended Enterprise concept (Browne, et. al. 1999; Vernadat, 2002) and the ENAPS Reference Models (Rolstadås 1998). It comprises 8 business processes to describe a generic structure of an ideal intra and inter integrated-extended enterprise. Below is a brief description of the business processes of the Integrated Extended Enterprise Reference Model: Co-Engineering, Customer Driven Design, Supplier Relationship Management, Customer Relationship Management, New Product Development, Obtaining Customer Commitment, Order Fulfillment/Supply Chain Management, and Customer Service

The reference model can be particularized to any enterprise and its core processes are chosen for modeling and simulation, in order to evaluate process improvement through Business Process Management. Extended Event-ProcessChain (eEPC) diagrams are used to model at different levels of detail the core processes (Figure 3). The detail level is defined according to the specification level of the activities included. The first level considers only general process functions; the second level considers specific activities of each function from the first level; and in the third level a deeper specification of activities is achieved for the specific functions from the second level, furthermore, material and information flows can 
also be included. In order to guarantee an effective global analysis, it is necessary to develop models covering the function and control views (Scheer, 1999).

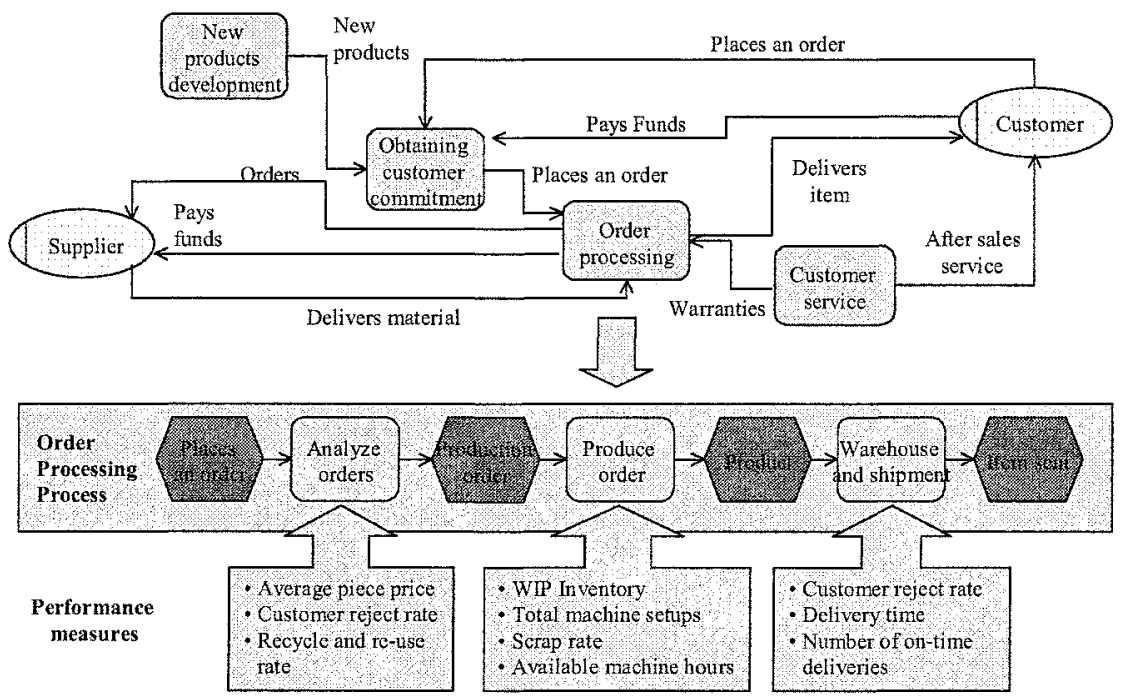

Figure 3 Extended Enterprise Reference (represented as eEPC diagrams)

\subsection{Decision making and simulation models}

Simulation allows the dynamic visualization of systems, and the interaction among their components in order to have a more realistic picture of the process or processes selected, and to understand process behavior. In this research, system dynamics simulation, discrete event simulations and program logic models were used:

System Dynamics simulation: The applied theory of system dynamics and dynamic systems modeling method come primarily from the work of Jay Forrester (Forrester 1980). The models are built based on feedback loops of key performance measures, cause-and-effect models, feedback influences and impacts of effects. Therefore enterprise models of behavior have been developed to demonstrate the effects and impacts of best practices implementation on performance measures (Molina and Medina 2003). An example of a dynamic model of a company including key manufacturing performance measures is presented in Figure 4.

Discrete event simulation: simulation is the most common method used to evaluate (predict) performance. The reason for this is that a quite complex (and realistic) simulation model can be constructed using actors, attributes, events and statistics accumulation. Business processes simulation can be performed, for example, in order to evaluate resource usage and to predict performance measures such as delivery time and cost, capacity usage, etc.

Program Logic Models: A Logic Model can be seen as a conceptual map that supports the evaluation of the possible impact in the implementation of a manufacturing practice. A logic model states short and long term impacts and what resources and methods are to be used ((Coffman, 1999; Alter, et al., 1997). The manufacturing practices are described and organized as program logic models (results, effects, impacts and benefits) allowing evaluation and planning of changes 
in the business process. For example, SMED (Single Minute Exchage of Dies) requires people to be trained, design a new set-up process, and implement the new procedure. The results of each of these activities are people trained and set up process designed and implemented. The changes that are required to implement the SMED practice are: flow of activities, abilities of operators and new set up instructions. If the practice is successful one might expect that a reduction of set up times will be achieved, more production time will be available, WIP (Work in Process) and costs will be reduced and the company will be expecting to increase its profit. This is a description of system dynamic model, where a cause-effect impact of different performance measures is described to evaluate the impact of a manufacturing practice.

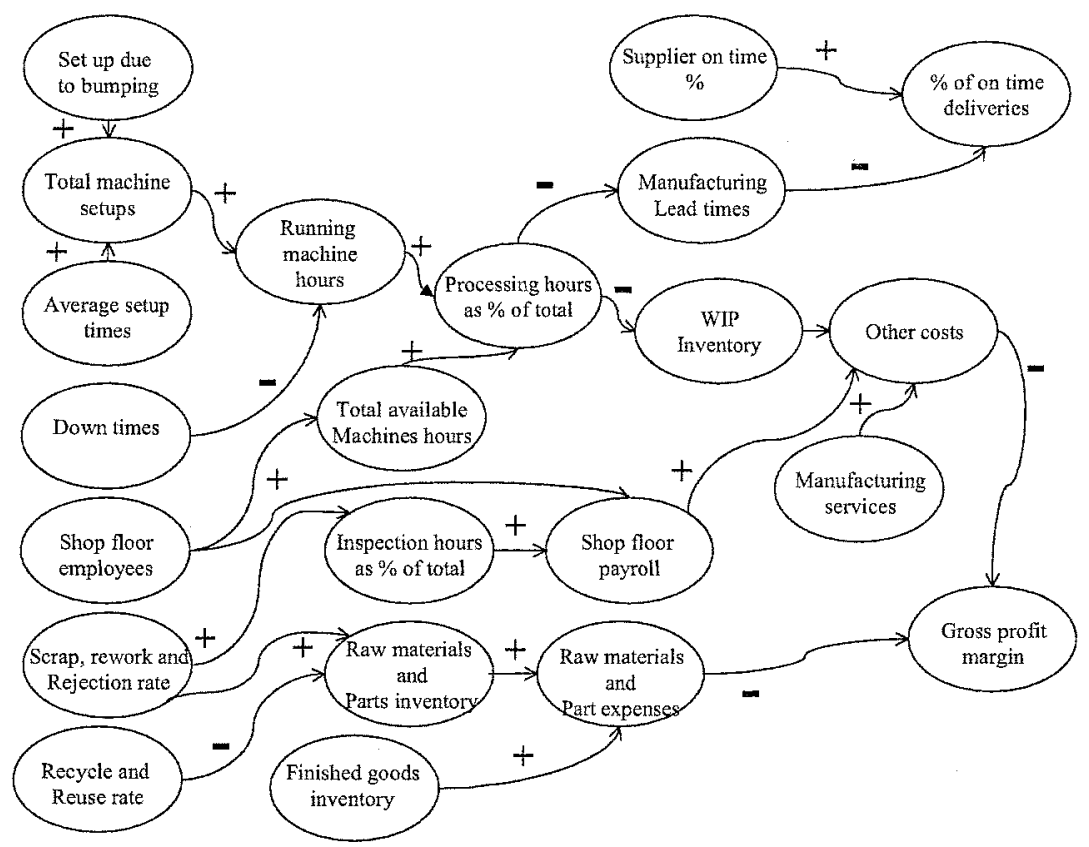

Figure 4 Key manufacturing performance measures described in a system dynamic model.

From several research and consulting projects developed at our research group, a Database of Best Manufacturing Practices has been collected. Results of this investigation are organized using Program Logic Models. The best manufacturing practices database has been developed and organized according to a logic model structure, which describes the benefits expected, and performance measures that a practice might influence, in order to evaluate their feasibility and effectiveness of implementation to optimize critical performance measures (Table 1).

Once the enterprise's (manufacturing and service) process is understood using the simulation tools, it is usually necessary to propose changes in order to improve the opportunity areas identified, e.g. by implementing SMED (a Best Manufacturing Practices). In the database, manufacturing practices are organized into activities, outputs, changes/effects, impacts and benefits - allowing the evaluation of the 
impact of implementing a best practice. The combination of System Dynamic models with Logic Models allows a systemic understanding of the impact of the implementation of best manufacturing practices.

Table 1. Description of best manufacturing practice using Program Logic Models

\begin{tabular}{|c|c|c|c|c|}
\hline Activities & Outputs & Changes/Effects & Impacts & Benefits \\
\hline $\begin{array}{l}\text { All necessary } \\
\text { activities to } \\
\text { implement a } \\
\text { best } \\
\text { manufacturin } \\
\text { g practice: } \\
\text { Train } \\
\text { Design } \\
\text { Implement } \\
\text { Evaluate }\end{array}$ & $\begin{array}{l}\text { Immediate } \\
\text { results of } \\
\text { activities: } \\
\text { People } \\
\text { trained } \\
\text { Process } \\
\text { designed } \\
\text { Process } \\
\text { executed }\end{array}$ & $\begin{array}{l}\text { Changes in business } \\
\text { processes: } \\
\text { Flow of activities and } \\
\text { information } \\
\text { Availability of data, } \\
\text { Information, and } \\
\text { knowledge } \\
\text { Human capital: } \\
\text { knowledge, skills and } \\
\text { abilities } \\
\text { Technological capital: } \\
\text { capacity, capabilities, and } \\
\text { usage. } \\
\text { Organization: practices, } \\
\text { procedures, methods, and } \\
\text { tools. }\end{array}$ & $\begin{array}{l}\text { Impact on } \\
\text { performance } \\
\text { measures: } \\
\text { Quality } \\
\text { Volume } \\
\text { Time } \\
\text { Cost } \\
\text { Flexibility } \\
\text { Environment }\end{array}$ & $\begin{array}{l}\text { Operational: } \\
\text { value added } \\
\text { per strategy, } \\
\text { process and } \\
\text { resource } \\
\text { Economics: } \\
\text { Profit / ROI } \\
\text { Strategic: } \\
\text { innovation, } \\
\text { excellence, } \\
\text { customer } \\
\text { focus. }\end{array}$ \\
\hline
\end{tabular}

\subsection{Business Process Intelligence tools and Business Process Management Systems}

Business Process Management (BPM) is the set of theories, techniques, methods, tools and applications that support the design and development of Business Process Management Systems (BPMS). BPMSs are software platforms that support the definition, execution, and tracking of business processes. Proper analysis of BPMS execution logs can yield important knowledge and help organizations improve the quality of their business processes and services to their business partners. BPMSs allow the execution of company processes based on workflow technology. In addition, Business Process Intelligence (BPI) allows users to analyze completed process executions from both a business- and an IT perspective. IT analysts will be interested in viewing detailed, low-level information such as average execution time per process or the length of the work queues of human or technological resources. Business users will instead be interested in higher-level information, such as the number of 'successful' process executions, or the characteristics of processes that did not meet the customer's expectations. The analysis capabilities of BPI can also be applied to analyze the design of a process model - in particular for identifying techniques to improve an existing process definition and/or the use of Information Technology. Therefore the utilization of Business Process Management Systems, together with BPI analysis capabilities, allow companies to support change using a technology driven approach.

\section{EXPERIENCIES IN APPLYING THE EIE FRAMEWORK}

An OEM (Original Equipment Manufacturer) has been working on the improvement of its Product Delivery System (PDS) through an integrated flow based on a Business Process Management System in order to satisfy their customer needs. A 
Product Delivery System is divided in the following cycles: customer order cycle (customer-retailer), replenishment cycle (retailer-distributor), manufacturing cycle (distributor-manufacturer), and procurement cycle (manufacturer-supplier). These cycles are co-ordinated and aligned in order to decrease the Total Cycle Time (receipt of order, planning, supply, manufacturing, warehousing and delivery). The EIE reference model was used to guide the design and implementation of the PDS in the following manner:

Competitive strategies were defined in order to achieve Operational Excellence. The following strategies were selected to achieve this objective: integration of the product delivery system flow, competitive excellence tools deployment (5S, TPM, Setup, Mistake Proofing, Root Cause Analysis), cost savings, commercial, operational and financial key initiatives and people cultural change.

Value Chain Strategies were defined in order to support these competitive strategies. These included: collaboration approach for the domestic market with customers and suppliers, aiming to materialize the concept of the 'virtual factory'. Horizontal integration was achieved by sharing commercialization resources with Business Units in the Northern American Operations and consolidating Asian Suppliers.

Production Strategies were set to satisfy customers' demands of different nature. These were defined as follows: Make to Stock (MTS) for the domestic market and Make to Order (MTO) for the exports market.

The core process defined was Order Processing (Product Delivery Process), which was supported by the PDS. The process was divided into different cycles, which could be addressed in turn in order to achieve internal goals to reduce weaknesses, always having in mind that these goals had to lead to the drivers of the company and to specific results

Performance indicators were defined to provide feedback about the company's progress toward achieving its strategic objectives:

- Competitive Strategy: cost reductions and time reductions

- Value Chain Strategy: cost reduction and increased flexibility by using local suppliers. Cost reduction by sharing resources for commercialization and purchasing.

- Production Strategy: reduced inventory level for exportation market (MTO), and setting of optimal inventory levels for national market (MTS).

- Process measures:

- Reduction of Customer Order Cycle and Replenishment Cycle

- Manufacturing Cycle: minimize setup times and increase mix model production

- Procurement Cycle: reduction of suppliers' lead-time negotiation, cost savings.

- Strategic decisions to evaluate:

- Customer Order Cycle: $80 \%$ Sales by Web, Forecast planning by Web, Customer Orders Status and Shipment using Web; and Warranty Online

- Replenishment Cycle: outsource logistic operator and automated receiving and warehousing process. 
- Manufacturing Cycle: facility's re-layout based in material flow concept and line flexibility, implement SMED (Single Minute Exchange of Dies), and redesign allocation algorithm for mix model production

- Procurement Cycle: 90\% suppliers online (automated purchase orders), redesign supplier's negotiation process and $50 \%$ of part numbers in Kanban Online.

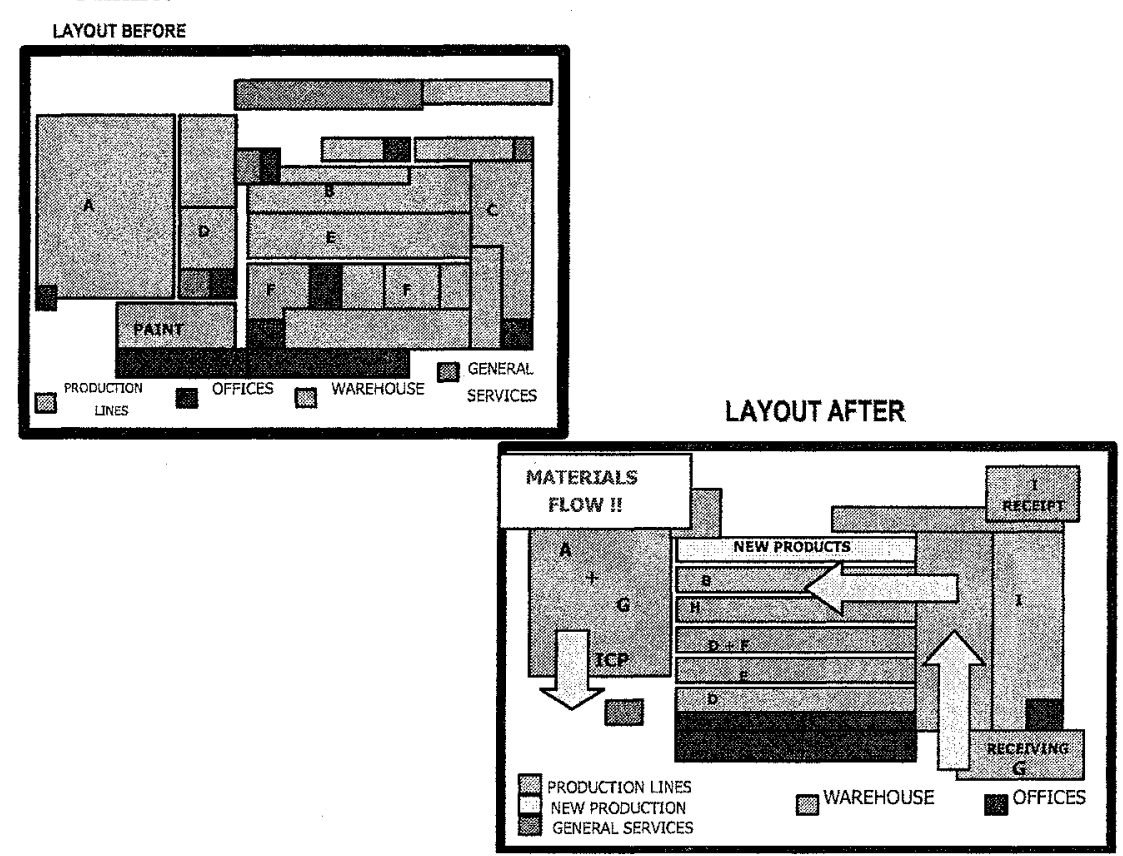

Figure 5 Layout redesign to allow an improved Product Delivery Process

The strategies were evaluated and the decision to redesign the Product Delivery Process and implement a Business Process Management system to support the process execution was made. The BPM system allows customer and supplier to use the Web for different operations, and the system is connected to the ERP (Enterprise Resource Planning) and MES (Manufacturing Execution System) on the shop-floor. The layout of the plant was redefined and the best manufacturing practice of SMED (Single Minute Exchange of Dies) was implemented (Figure 5). The new process was monitored and analyzed in order to evaluate the impact on the different performance measures.

\section{CONCLUSION AND FURTHER WORK}

A few years ago, manufacturing industry, especially in Mexico, was characterized as a labor intensive sector; however, the trend is changing, since this industry is not distinguished any more because of the low wages it used to pay. Today manufacturing in Mexico is evolving to a more knowledge-based industry, and it is hoped that this will continue in the future. Since the characteristic component of Enterprise Integration Engineering and Business Process Management is knowledge, this research emphasizes the point where the future of manufacturing lies. 
There is a need for better practices of knowledge acquisition, visualization and use in manufacturing companies. Therefore it is important to develop new strategies, methodologies and tools that allow enterprise to document, evaluate and apply changes in its business process, using formal enterprise reference models. These models can be used to analyze, monitor and determine positive or negative impacts of best practice implementation using a low risk and systematic process improvement method. This paper describes a reference model for Enterprise Integration Engineering to guide and support the implementation of Business Process Management. The reference model includes four elements: strategy and performance evaluation systems, reference models for enterprise modeling, decision making and simulation models, as well as business Process Management Systems and Business Process Intelligence tools. This reference framework has allowed Mexican companies to achieve change management using a systematic and holistic approach. The framework includes a set of tools for modeling and simulation. A summary of a case study has been presented to demonstrate the use of the framework.

\section{Acknowledgments}

The research reported in this paper is part of a CEMEX Grant. The authors wish to acknowledge the support of this grant in the preparation of the manuscript.

\section{REFERENCES}

Alter, Catherine and Egan, Marcia (1997) Logic Modelling: A Tool for Teaching Critical Thinking in Social Work Practice. J of Social Work Education 33(1)

Bernus P., Nemes L. and Schmidt G. (2003) Handbook on Enterprise Architecture. Berlin : Springer.

Browne J., Hunt I., Zhang J. (1999) The Extended Enterprise. In Handbook of Life Cycle Engineering: Concept, Methods and Tools. Molina A., Kusiak, A. and Sanchez (Eds). Kluwer Academic Publishers. 3-29

Coffman L. (1999) Learning From Logic Models: An Example of a Family/School Partnership Program. Harvard Family Research Project, http://www.gse.harvard.edu/hfrp/pubs.html.

Forrester, J.W. (1968). Principles of systems : text and workbook. Wrigh-Allen Press, Cambridge, MA.

Grigoria D., Casatib F., Castellanos M., Dayalb U., Sayalb M., Shanb M-C. (2004) Business Process Intelligence, Computers in Industry 53(3) 321-343.

Hill, T. (1989) Manufacturing Strategy. Homewood, IL: Richard D. Irwin.

Hope J., and Hope T. (1997) Competing in the Third Wave. Boston: Harvard Business School Press

Molina A. and Medina V. (2003) Application of Enterprise Models and Simulation Tools for the evaluation of the impact of best manufacturing practices implementation. Annual Reviews in Control, 27(2) 221-228.

Rolstadås, A. (1998) Enterprise performance measurement. International Journal of Operations \& Production Management. 18(9) 989-999.

Scheer, A-W. (1999) ARIS - Business Process Modelling. New York : Springer

Vernadat F.B. (2002) Enterprise Modeling and Integration (EMI): Current Status and Research Per-spectives. Annual Reviews in Control 26. 15-25. 